\title{
KUALITAS INFORMASI TERKAIT PENERAPAN HASIL DESAIN REKAM MEDIS GIGI DI KLINIK SAKINAH KABUPATEN JEMBER
}

\author{
${ }^{1}$ Rinda Nurul Karimah, ${ }^{2}$ Ida Nurmawati \\ ${ }^{1,2}$ Program Studi Rekam Medik Jurusan Kesehatan Politeknik Negeri Jember \\ Jalan Mastrip Kotak Pos 164 Jember \\ rinda_md@yahoo.com
}

\begin{abstract}
Tooth is a part of the human body that can be used to identify scene of death case as well as fingerprints and blood type; especially if its medical record is well managed. Klinik Sakinah is a primary care clinic and has FKTP (Health Facility Level One) of BPJS status in Jember, provide dental health services, but it has no medical record kept specifically for dental services. The purpose of this research was to design a dental record form as needed as primary care clinic and know the quality of information produced. This research is a qualitative descriptive analysis method. Qualitative data collection is done by observation, interview and discussion, while the analytical method used to determine the quality of information produced is done by giving questionnaires to users of the design. Total subjects in this reseach were four people associated with the user dental records, there arethe head of sakinah clinic, dentists, and administrative personnel which selected by purposive sampling. The results of dental records design contain patient data, general condition, odontogram, anesthesia and examination results, and financing. After the use of the design of dental 1 records form, increased information quality in aspects of accuracy from $50 \%$ to $80 \%$, the completeness of $60 \%$ to $75 \%$, and the clarity of $66 \%$ to $85 \%$. It is advisable to complete the dental records throughout the medical records document of patients who are family folder arrangement for maximum performance Health Facility Level One.
\end{abstract}

Key words : dental record, medical record, information quality

\begin{abstract}
Abstrak
Gigi merupakan salah satu bagian tubuh manusia selain sidik jari dan golongan darah yang dapat digunakan sebagai sarana identifikasi sebuah kasus kematian, khususnya bila rekaman data gigi semasa hidup seseorang disimpan secara baik. Klinik Sakinah merupakan salah satu klinik FKTP (Fasilitas Kesehatan Tingkat Pertama) BPJS Kesehatan di Kabupaten Jember yang memberikan pelayanan kesehatan gigi, namun belum terdapat berkas rekam medis khusus untuk pelayanan gigi. Tujuan penelitian ini adalah untuk merancang berkas rekam medis gigi sesuai kebutuhan Klinik Sakinah sebagai FKTP dan mengetahui kualitas informasi yang dihasilkan. Penelitian ini merupakan penelitian kualitatif dengan metode analisis deskriptif. Pengumpulan data kualitatif dilakukan dengan observasi, wawancara mendalam, dan diskusi, sedangkan metode analisis deskriptif digunakan untuk mengetahui kualitas informasi yang dihasilkan dilakukan dengan memberikan kuesioner kepada pengguna hasil desain.Subjek penelitian berjumlah empat orang yang terkait dengan pengguna (user) rekam medis gigi yaitu pimpinan klinik Sakinah, dokter gigi, dan tenaga administrasi klinik Sakinah yang dipilih dengan teknik purposive sampling.Hasil desain rekam medis gigi klinik Sakinah berisi data pasien, kondisi umum pasien, odontogram, prosedur anestesi dan hasil pemeriksaan, serta pembiayaan.Setelah penggunaan desain formulir rekam medis gigi, kualitas informasi meningkat dalam aspek keakuratan dari 50\% menjadi 80\%, kelengkapan dari 60\% menjadi 75\%, dan kejelasan dari $66 \%$ menjadi 85\%.Disarankan melengkapi formulir rekam medis khusus gigi pada seluruh berkas dokumen rekam medis pasien yang penataannya secara family folderagar capaian FKTP lebih maksimal.
\end{abstract}

Kata kunci: rekam medis gigi, rekam medis, kualitas informasi. 
Rinda Nurul K, Ida Nurmawati, Kualitas Informasi Terkait Penerapan Hasil desain Rekam Medis Gigi di Klinik Sakinah Kabupaten Jember

\section{PENDAHULUAN}

Gigi merupakan salah satu bagian tubuh manusia selain sidik jari dan golongan darah yang dapat digunakan sebagai sarana identifikasi dalam sebuah kasus kematian, khususnya bila rekaman tentang data gigi semasa hidup seseorang disimpan secara baik. $^{1}$ Identifikasi merupakan prosedur penentuan identitas individu melalui perbandingan data dari individu yang diperiksa dengan data orang yang disangka sebagai individu tersebut. ${ }^{2}$ Beberapa sumber menyebutkan bahwa metode identifikasi melalui gigi merupakan metode yang tebukti cepat dan akurat serta tidak memerlukan biaya yang besar. Metode identifikasi melalui gigi ini sangat menguntungkan terutama pada kasus besar dimana korban mengalami kerusakan parah pada wajah dan sidik jari. ${ }^{3}$

Rekam medis adalah berkas yang berisikan catatan dan dokumen tentang identitas pasien, pemeriksaan, pengobatan, tindakan, dan pelayanan lain yang telah diberikan kepadapasien. Setiap dokter atau dokter gigi dalam menjalankan praktik kedokteran wajib membuat rekam medis. ${ }^{4}$ Rekam medik dipandang sebagai sarana komunikasi antar tenaga medis dalam memberikan pelayanan kepada pasien sehingga pelayanan kesehatan yang komprehensif dan optimal dapat diperoleh setiap pasien. $^{5}$

Rekam medik kedokteran gigi merupakan dokumen yang sangat penting karena didalamnya tercatat secara rinci mengenai kondisi pasien dan tindakan kedokteran yang diberikan kepada pasien. Rekam Medik Kedokteran Gigi dapat berupa catatan tertulis atau dalam bentuk elektronik yang berisikan informasi lengkap dan akurat mengenai identitas pasien, diagnosis, perjalanan penyakit, kode penyakit ICD 10, pengobatan dan tindakan medis serta dokumentasi hasil pemeriksaan. ${ }^{5}$ Kewajiban membuat rekam medik tidak hanya ditujukan kepada setiap individu dari tenaga medis, namun juga ditujukan kepada fasilitas pelayanan kesehatan seperti klinik kesehatan. Permenkes RI nomor 9 tahun 2014 tentang Klinik menyebutkan bahwa setiap klinik mempunyai kewajiban menyelenggarakan rekam medis. ${ }^{6}$

Klinik Sakinah Kabupaten Jember merupakan klinik pratama yang telah bekerja sama dengan Badan Penyelenggara Jaminan Sosial (BPJS) Kesehatan dalam pembiayaan kesehatan. Klinik Sakinah merupakan salah satu klinik di Kabupaten Jember yang memberikan pelayanan kesehatan gigi.Rekam medis di Klinik Sakinah menggunakan Family Folder, dimana rekam medis dari anggota keluarga disusun menjadi satu folder rekam medis.

Hasil penelitian dari murniwati dkk memperlihatkan bahwa tingkat pengetahuan dokter gigi di Puskesmas dan Rumah Sakit Kota Padang pada tahun 2012terhadap syarat lengkap, item penting, manfaat dan aspek medikolegal rekam medis gigi masih rendah yaitu kurang dari $55 \%$. Hal ini disebabkan oleh tidak tersedianya sarana rekam medis gigi yang sesuai standar nasional. ${ }^{3}$ Penelitian morgan dalam British dental journal dengan judul Quality evaluation of clinical records of a group of general dental practitioners entering a quality assurancemenunjukkan hanya 44\% rekam medis yang lengkap dari 207 kasus yang ditelitidikarenakan sedikitnya informasi terkait standar rekam medis klinis. ${ }^{7}$

Hasil studi pendahuluan diketahui bahwa di Klinik Sakinah Kabupaten Jember belum terdapat berkas rekam medis khusus untuk pelayanan gigi.Rekam medis gigi di Klinik Sakinah masih jadi satu dengan berkas rekam medis pelayanan umum.Berdasarkan uraian tersebut peneliti tertarik untuk merancang berkas rekam medis gigi di Klinik Sakinah Kabupaten Jember dan menganalisis kualitas informasi yang dihasilkan.

\section{METODOLOGI}

Penelitian ini merupakan penelitian kualitatif, dimana peneliti menggali informasi tentang kebutuhan pengguna dalam mendesain berkas rekam medik gigi klinik Sakinah meliputi aspek isi, penggunaan, dan ciri fisik.Kebutuhan pengguna terkait desain rekam medis dikumpulkan melalui observasi, wawancara mendalam (in dept interview) dan diskusi dengan subyek penelitian.Unit analisis penelitian sebanyak empat orang yaitu pimpinan klinik (R1), dokter gigi (R2), dan dua orang tenaga administrasi 1 (R3 dan R4) di klinik Sakinah yang dipilih dengan metode purposive sampling. Adapun metode analisis kualitas informasi yang dihasilkan setelah implementasi hasil desain formulir rekam medis gigi adalah dengan mengguanakan metode analisis deskriptif.

\section{HASIL DAN PEMBAHASAN}

Penelitian ini menghasilkan suatu desain rekam medis gigi sesuai kebutuhan klinik Sakinah sebagai FKTP, dan hasil pengukuran kualitas informasi dari implementasi desain.

Desain rekam medis gigi dihasilkan melalui beberapa tahapan metode perancangan, sebagai berikut: tahap pertama adalah identifikasi kebutuhan pengguna (user) ditujukan untuk memperoleh informasi terkait kebutuhan pengguna terhadap formulir rekam medis gigi,agar desain yang dihasilkan dapat sesuai kebutuhan pengguna.Tahap kedua dilakukan proses desain, berdasarkan informasi yang diperoleh dari tahap satu, teori desain formulir medis dan regulasi yang berlaku. Tahap ketiga dilakukan diskusi dari desain yang dihasilkan pada tahap kedua, ditujukan untuk 
penyempurnaan dari desain agar lebih sesuai lagi dengan kebutuhan pengguna. Tahap keempat, dilakukan implementasi hasil desain. Pengukuran kualitas informasi dilakukan setelah implementasi selama satu bulan dari desain hasil perancangan.

Hasil dari tahapan penelitian ini adalah sebagai berikut:

1. Identifikasi Kebutuhan Pengguna : Identifikasi kebutuhan pengguna merupakan salah satu kegiatan dalam manajemen formulir yang bertujuan untuk menentukan bentuk, format, maupun isi formulir sesuai dengan kebutuhan pengguna. Hasil identifikasi kebutuhan pengguna dapat dijadikan acuan atau panduan dalam desain formulir agar formulir tersebut dirancang secara efisien dan tersedia bagi pengguna. ${ }^{8}$ Identifikasi kebutuhan pengguna dilakukan dengan wawancara kepada tenaga administrasi, dokter gigi, dan pimpinan klinik Sakinah. Berdasarkan hasil wawancara diketahui bahwa perlu adanya formulir khusus untuk rekam medis gigi, berkaitan dengan proses akreditasi klinik yang mensyaratkan adanya rekam medis gigi.Kebutuhan formulir rekam medis gigi sendiri sangat penting karena isi formulir rekam medis gigi tidak sama dengan formulir rekam medis pasien umum. Hasil wawancara dengan responden 2 (R2) diketahui bahwa formulir rekammedis gigi membutuhkan informasi tentang kondisi gigi pasien sedangkan dalam formulir rekam medis yang selama ini digunakan di klinik Sakinah belum bisa menyediakan informasi tersebut karena formulir yang digunakan adalah formulir untuk pasien ir rekam medis gigi umum.Berdasarkan hasil wawancara yang membedakan rekam medis umum dengan rekam medis gigi adalah adanya informasi tentang odontogram. Odontogram adalah suatu gambar peta mengenai keadaan gigi di dalam mulut yang merupakan bagian yang tidak bisa dipisahkan dari rekam medik kedokteran gigi. Tujuannya adalah untuk mengetahui keadaan gigi geligi dari pasien. ${ }^{5}$ Data odontogram merupakan salah satu data yang terlampir dalam rekam medik gigi. Odontogram merupakan data yang penting dalam proses identifikasi karena memuat data tentang jumlah, bentuk, susunan, tambalan, protesa gigi, dan sebagainya. Odontogram sedapat mungkin dibuat secara teliti sehingga dapat dibedakan dan diketahui secara pasti keadaan gigi dan jenis tindakan yang dilakukan.Pentingnya informasi odontogram inilah yang menyebabkanformulir rekam medis gigi harus dibuat secara terpisah dari formulir rekam medis umum. Hasil wawancara dengan R2, R3 dan R4 diketahui bahwa isi formulir rekam medis gigi yang dibuat harus mencakup identitas pasien, riwayat penyakit pasien, kondisi kesehatan pasien, odontogram, pemeriksaan gigi. Sedangkan isi rekam medis gigi dari aspek administratif, selain identitas pasien responden menginginkan adanya informasi tentang biayapemeriksaan. Hal ini penting dikarenakan klinik Sakinah merupakan FKTP dimana sistem pembiayaan kepesertaannya BPJS nya adalah secara kapitasi dan fee for service untuk pasien umum.Kebutuhan pengguna yang selanjutnya adalah aspek penggunaan. Aspek penggunaan berfokus pada pengguna rekam medis dalam hal pengisisan rekam medis, jumlah formulir yang diperlukan klinik dalam satu tahun, dan tempat penyimpanan formulir rekam medis gigi. Pengguna langsung rekam medis yaitu petugas yang melakukan pengisian formulir rekam medis gigi di Klinik Sakinah adalah seorang dokter gigi sebagai pemberi layanan dan dua orang tenaga administrasi dengan latar belakang D3 Kebidanan. Tempat penyimpanan formulir rekam medis gigi dan rekam medis pasien umum Klinik Sakinah berada dalam satu tempat berupa map kertas. Sedangkan untuk kebutuhan formulir rekam medis gigi dalam satu tahun disesuaikan dengan jumlah pasien yaitu sekitar 650 pasien.Ciri fisik merupakan aspek yang sangat penting untuk diperhatikan dalam perancangan formulir rekam medis gigi karena berkaitan dengan keterbacaan formulir, ukuran kertas, lama retensi, berat kertas, dan jumlah lembaran formulir. Informasi dari pimpinan klinik diketahui bahwa kertas yang digunakan haruslah kertas yang tidak mudah sobek karena masa retensi formulirrekam medis gigi di Klinik sakinah adalah 5 tahun. Warna yang dipilih untuk desain formulir rekam medis gigi klinik Sakinah adalah putih untuk kertas dan hitam untuk tintanya. Desain formulir rekam medis gigi yang dirancang harus efisien dan efektif. Efisien penggunaan material dan efektif dalam memenuhi kebutuhan informasi pengguna.

2. Desain Berkas Rekam Medis Gigi Klinik Sakinah :formulir rekam medis gigi dirancang berdasarkan aspek isi, penggunaan, dan ciri fisik. Berdasarkan aturan perancangan formulir, aspek isi formulir merupakan bagian yang sangat penting karena menyangkut kebutuhan informasi pengguna. ${ }^{8}$ Standar nasional rekam medik kedokteran gigi, formulir rekam medis gigi berisikan identitas pasien, keadaan umum pasien, odontogram, data perawatan kedokteran gigi, dan nama dokter yang merawat. Identitas pasien terdiri dari nomor file, tanggal pembuatan status, nama, jenis kelamin, tempat dan tanggal lahir, alamat rumah (nomor telepon/handphone), pekerjaan, serta alamat kantor. Data keadaan umum berisikan golongan darah, tekanan darah, adakah kelainan hemophilia, penyakit jantung, penyakit diabetes, alergi terhadap obat dan makanan tertentu, dan penyakit tertentu seperti hepatitis, HIV. 
Rinda Nurul K, Ida Nurmawati, Kualitas Informasi Terkait Penerapan Hasil desain Rekam Medis Gigi di Klinik Sakinah Kabupaten Jember

Odontogram berisikan data tanggal pemeriksaan odontogram, denah gigi, hubungan oklusi, ada atau tidaknya torus palatinus dan torus mandibularis, palatum, supernumerary, diasterna sentral, serta ciri-ciri lainnya. Data perawatan berisi tanggal kunjungan, gigi yang dirawat, keluhan dan diagnose, tindakan yang dilakukan, paraf dokter, rontgen foto. ${ }^{1}$ Klinik sakinah merupakan klinik pratama yang memberikan pelayanan kesehatan primer kepada pasien dengan jumlah sumberdaya yang terbatas maka desain formulir yang dirancang harus sederhana namun dapat memenuhi kebutuhan pengguna dan sesuai dengan standar nasional rekam medik kedokteran gigi. Hasil perancangan formulir rekam medis gigi klinik Sakinah (gambar 1) telah sesuai dengan kebutuhan pengguna dan standar nasional rekam medis kedokteran gigi, dimana dalam desain rekam medis gigi klinik Sakinah terdapat informasi data pasien, keadaan umum pasien, odontogram, pemeriksaan dan perawatan, dan tanda tangan dokter yang melakukan perawatan.

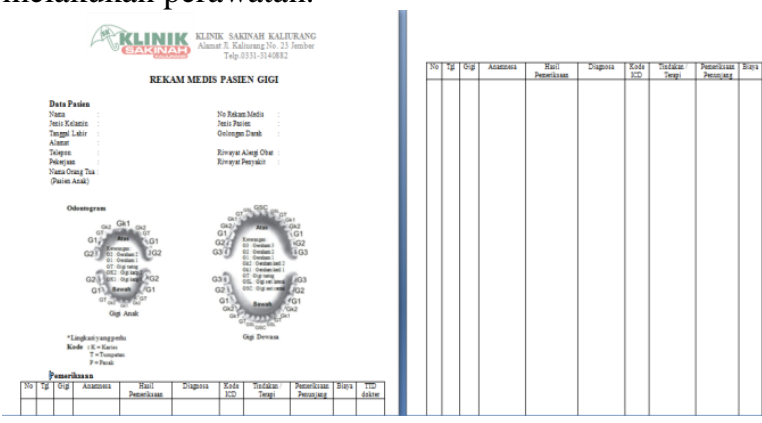

Gambar 1 Hasil desain awal berkas rekam medis gigi klinik Sakinah (tahap 2).

Uraian Hasil perancangan formulir rekam medis gigi klinik Sakinah yaitu data pasien terdiri dari nama; jenis kelamin; tanggal lahir; alamat; telepon; pekerjaan; nama orang tua untuk pasien anak; nomor rekam medis; dan jenis pasien, data keadaan umum terdiri dari golongan darah; riwayat alergi obat; dan riwayat penyakit, data odontogram terdiri dari gambar gigi geligi orang dewasa dan anak-anak beserta istilah gigi geligi, data pemeriksaan berisikan data perawatan kedokteran gigi terdiri dari tanggal kunjungan; gigi yang dirawat; anamnesa; hasil pemeriksaan; diagnose; kode ICD; tindakan/terapi; pemeriksaan penunjang; biaya; dan tanda tangan dokter gigi. Sedangkan data tekanan darah pasien dapat berubah-ubah setiap saat sehingga pengukuran tekanan darah harus dilakukan setiap pasien berkunjung.

Desain formulir rekam medis gigi berdasarkan aspek penggunaan dilihat dari latar belakang pendidikan pengguna, jenis penyimpanan berkas, dan kopi berkas selama satu tahun.Hasil identifikasi kebutuhan pengguna diketahui bahwa yang memanfaatkan langsung rekam medis gigi adalah tenaga administrasi dengan latar belakang D3 Kebidanan dan dokter gigi.Pengguna rekam medis gigi klinik Sakinah dengan latar belakang pendidikan perguruan tinggi memungkinkan untuk lebih mudah memahami desain formulir rekam medis gigi yang telah dirancang.Selain itu dokter gigi dan tenaga administrasi yang melakukan pengisian formulir rekam medis gigi telah terbiasa melakukan pengisian rekam medis sebelumnya. Rekam medis gigi klinik Sakinah akan disimpan dalam map kertas biasa yang dijadikan satu dengan rekam medis pasien umum. Oleh karena itu desain formulir tidak mempertimbangkan space untuk penjilidan maupun lubang seperti terlihat pada gambar 1 .

Kebutuhan rekam medis gigi di klinik Sakinah dalam setahun disesuaikan dengan jumlah pasien yaitu 650 pasien agar tidak terjadi pemborosan. Kopi formulir atau penggandaan formulir sebaiknya ditekan seminimum mungkin karena kopi ekstra formulir akan menyebabkan banyak kertas terbuang, membutuhkan penyimpanan arsip dinamis, dan menambah biaya. ${ }^{10,11}$ Menurut Huffman (1999), banyaknya kopi formulir menyebabkan tidak terpakainya formulir, hal ini meningkatkan ketidak-efisienan. ${ }^{10,11}$ Pertimbangan lain dalam desain formuliryang dibuat adalah formulir harus mampu mencatat pelayanan gigi pasien selama satu tahun atau sebanyak mungkin selama pasien berkunjung ke klinik sehingga kebutuhan jumlah formulir untuk satu pasien dalam satu tahun dapat seminimum mungkin. Berdasarkan pertimbangan tersebut desain formulir dibuat "bolak balik" agar dapat menampung banyak catatan pasien.Gambar 1 menunjukkan desain formulir "bolak balik" (depanbelakang).Desain formulir rekam medis gigi berdasarkan aspek ciri fisik adalah ukuran dan sifat khusus lainnya. Pada umumnya penggunaan formulir berukuran standar adalah cara yang baik, terutama jika untuk pengarsipan atau kopi formulir. ${ }^{10}$

Hasil identifikasi kebutuhan menunjukkan bahwa retensi di Klinik Sakinah dilakukan selama lima tahun. Berdasarkan standar nasional rekam medik kedokteran gigi diketahui masa untuk penyimpanan rekam data gigi pasien adalah paling sedikit selama lima tahun setelah pasien datang terakhir kalinya kepada dokter atau klinik. ${ }^{1}$ Ciri fisik yang perlu dipertimbangkan dalam desain formulir rekam medis gigi antara lain jenis kertas, tebal kertas, ukuran kertas, warna, dan jumlah lembaran formulir. Berdasarkan pertimbangan masa retensi di klinik Sakinah maka dibutuhkan desain formulir yang tidak mudah rusak, hal ini berkaitan dengan pemilihan jenis dan tebal kertas sehingga aspek permanency, durability, mutu penulisan kertas, dan keterbacaan 
terpenuhi.Permanency adalah berapa lama kertas dapat disimpan.Durability berhubungan dengan kesanggupan seseorang untuk mengelola kertas bekali-kali.Mutu penulisan kertas berhubungan dengan kemampuan kertas untuk dapat digunakan menulis dengan cepat dan rata dan kemampuan kertas untuk menerima tinta dari alat percetakan. Keterbacaan dipengaruhi oleh terutama interaksi kertas dengan cahaya atau kilatan dari kertas. ${ }^{8}$

Berdasarkan pertimbangan tersebut maka untuk formulir rekam medis gigi klinik Sakinah dipilih jenis kertas karton. Kertas karton merupakan jenis kertas yang tebaldengan berat sekitar 200 gr dan banyak digunakan untuk bahan cetakan kartu nama, catalog, company profile, brosur, paperbag, dan map. Hal ini menunjukkan bahwa kertas karton dapat digunakan dalam desain formulir rekam medis gigi dan memenuhi unsur permanency, durability, mutu penulisan kertas, dan keterbacaan. Peneliti juga melakukan pengujian dengan cara menulis diatas kertas karton dan hasilnya adalah peneliti dapat menulis dengan cepat dan rata pada kertas karton seperti halnya menulis pada kertas A4 atau buku tulis. Artinya kertas karton memenuhi unsur mutu penulisan kertas.Ciri fisik lainnya adalah penggunaan warna baik warna kertas maupun tinta.Huffman (1999) menyatakan bahwa tinta yang dipilih harus memberikan kontras yang semestinya pada kertas dan memberikan cetakan yang jelas, seragam, dan rata. Penggunaan lebih dari satu warna tinta menambah biaya formulir dan mempersulit proses fotokopi dan scanning ke sistem pencitraan optis. ${ }^{8}$

Hasil identifikasi kebutuhan pengguna diketahui bahwa warna kertas maupun tinta digunakan warna yang netral yaitu hitam putih.Berdasarkan kebutuhan pengguna dan aturan perancangan formulir maka peneliti memilih kertas karton putih dengan tinta hitam.Ciri fisik selanjutnya adalah ukuran kertas dan jumlah lembaran formulir rekam medis gigi.Hasil wawancara diketahui bahwa desain formulir harus efisien dalam penggunaan material atau kertas.Jumlah formulir juga berhubungan dengan biaya cetak formulir, kebutuhan kopi formulir jika diperlukan, dan penyimpanan. Oleh karena itu desain formulir yang dibuat adalah satu lembar dengan struktur "bolak balik" dan ukuran 14,5 x 21 atau setengah ukuran A4 seperti pada gambar 1.

3. Diskusi Hasil Desain Berkas Rekam Medis Gigi Klinik Sakinah :Tahap selanjutnya setelah desain formulir rekam medis gigi selesai dilakukan adalah melakukan diskusi dengan pihak klinik Sakinah mengenai hasil desain formulir. Berdasarkan hasil diskusi diperoleh masukan dari dokter gigi yaitu penggunaan istilah medis baik untuk gigi geligi maupun kode. Gambar 2 dan 3 menunjukkan perbedaan penggunaan istilah gigi geligi dan kode sebelum dan sesudah diskusi dengan pihak klinik Sakinah. Awal perancangan peneliti menggunakan istilah dalam bahasa Indonesia, kemudian mendapatkan masukan dari dokter gigi klinik Sakinah untuk menggunakan istilah kedokteran baik untuk gigi geligi maupun kode. Selain itu dalam diskusi diperoleh masukan untuk penambahan kode yaitu caries, filling, protesa, missing, radix, dan calculus.

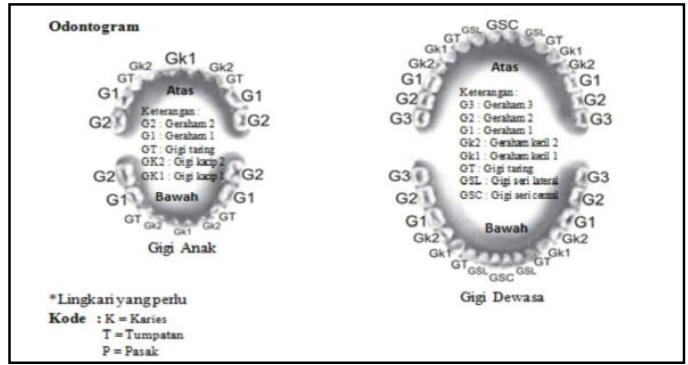

Gambar 2 Penggunaan istilah formulir sebelum diskusi

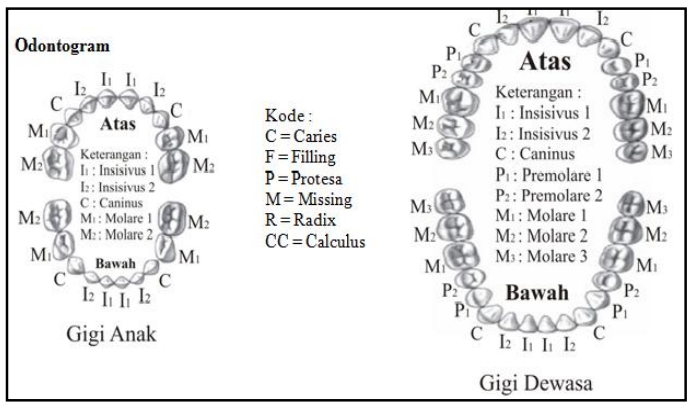

Gambar 3 Penggunaan istilah setelah diskusi

Pada saat diskusi juga diperoleh masukan dari manajer atau pimpinan klinik Sakinah berkaitan dengankebutuhan untuk akreditasi klinik.Pimpinan klinik memberikan saran untuk menambah informasi tentang anestesi dan pemantauan pasca anestesi.Menurut pimpinan klinik formulir rekam medis gigi yang sesuai dengan penilaian akreditasi klinik harus mencantumkan anestesi dan pengawasan anestesi pasien.Gambar 4 menunjukkan adanya penambahan informasi untuk anestesi dan observasi anestesi. 
Rinda Nurul K, Ida Nurmawati, Kualitas Informasi Terkait Penerapan Hasil desain Rekam Medis Gigi di Klinik

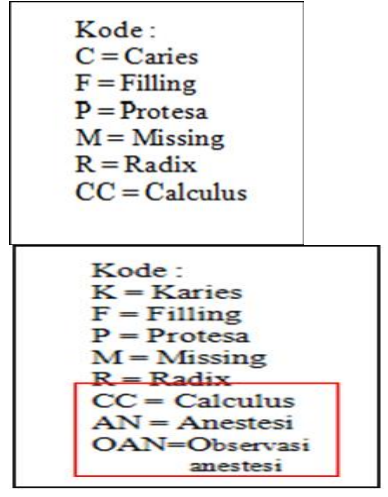

Gambar 4 Kode setelah diskusi

Diskusi desain formulir rekam medis gigi dengan pihak Klinik Sakinah tidak hanya membahas isi formulir rekam medis gigi saja tetapi juga fisik dari formulir.Aspek fisik sudah sesuai dengan kebutuhan pengguna, namun untuk ukuran formulir rekam medis gigi perlu disesuaikan dengan ukuran rekam medis pasien umum agar terlihat rapi secara estetika. Ukuran formulir rekam medis gigi pada saat awal desain adalah $14,5 \times 21$ $\mathrm{cm}$, berubah menjadi $16,3 \times 21,5 \mathrm{~cm}$. Desain akhir formulir rekam medis gigi klinik Sakinah setelah dilakukan diskusi terlihat pada gambar 5 .

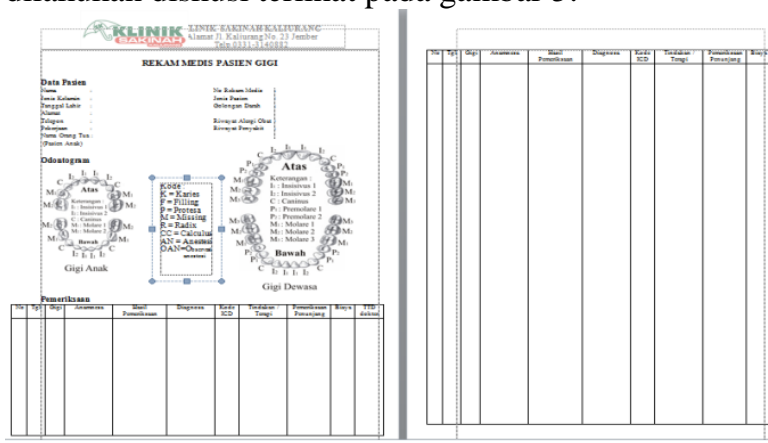

Gambar 5 Hasil desain akhir berkas rekam medis gigi klinik Sakinah (tahap 3)

4. Implementasi Desain Berkas Rekam Medis Gigi Klinik Sakinah :Diskusi desain formulir rekam medis gigi menghasilkan desain formulir rekam medis gigi yang nantinya akan digunakan di Klinik Sakinah. Sebelum digunakan untuk melakukan pencatatan pasien gigi di Klinik Sakinah maka oleh peneliti dilakukan implementasi di Klinik. Implementasi desain formulir rekam medis gigi bertujuan untuk mengetahui apakah desain formulir yang telah dirancang dapat digunakan petugas kesehatan dan sudah memenuhi kebutuhan informasi pengguna di Klinik Sakinah. Implementasi desain formulir dilakukan selama dua hari yaitu pada tanggal 15-16 Oktober 2016. Hasil implementasi diketahui bahwa petugas kesehatan di Klinik Sakinah mampu menggunakan formulir rekam medis gigi dalam arti mampu melakukan pengisian formulir sesuai dengan tujuan dari isi formulir. Selain itu data yang ada dalam formulir rekam medis gigi telah memenuhi kebutuhan informasi dari pengguna rekam medis gigi di Klinik Sakinah.

5. Kualitas Informasi

Analisis kualitas informasi dilakukan dengan metode analisis deskriptif. Responden diberi kuesioner berisi item pertanyaan terkait kualitas informasi, diberikan sebelum implementasi desain rekam medis gigi dan setelah penggunaan desain rekam medis gigi selama satu bulan. Hasil yang diperoleh setelah penggunaan desain formulir rekam medis gigi, kualitas informasi meningkat dalam aspek keakuratan dari $50 \%$ menjadi $80 \%$, kelengkapan dari $60 \%$ menjadi $75 \%$, dan kejelasan dari $66 \%$ menjadi $85 \%$. Sedangkan aspek fleksibilitas mengalami penurunan dari $51 \%$ menjadi $49 \%$ dan aspek ketetapan waktu tetap yaitu sebesar $72 \%$.

\section{KESIMPULAN}

Perancangan desain rekam medis gigi klinik Sakinah berdasarkan kebutuhan informasi pengguna, aturan perancangan formulir, dan standar nasional rekam medik kedokteran gigi.Berkas rekam medis gigi klinik Sakinah berisikan data pasien, keadaan umum pasien, odontogram, dan pemeriksaan. Kualitas informasi meningkat pada implementasi hasil desain rekam medis gigi dalam aspek keakuratan dari 50\% menjadi $80 \%$, kelengkapan dari $60 \%$ menjadi $75 \%$, dan kejelasan dari $66 \%$ menjadi $85 \%$.

Saran pada penelitian ini adalah manajemen klinik Sakinah agarmelengkapi formulir rekam medis khusus gigi pada seluruh berkas dokumen rekam medis pasien yang penataannya secara family folder agar capaian FKTP lebih maksimal.

\section{UCAPAN TERIMA KASIH}

Peneliti mengucapkan terima kasih kepada Pusat Penelitian dan Pengabdian Kepada Masyarakat (P3M)Politeknik Negeri Jember atas dukungan pendanaan yang telah diberikan sehingga penelitian dengan judul "Kualitas informasi terkait penerapan desain berkas rekam medis gigi di Klinik Sakinah Kabupaten Jember" dapat terlaksana dengan baik sesuai rencana.

\section{DAFTAR PUSTAKA}

[1] Quendangen A, Hamurwono GB, Sahelangi P, Rosita R, Suseno U, Lebang Y. Standar Nasional Rekam Medik Kedokteran Gigi Cetakan II. Jakarta: Direktorat Jenderal Bina Pelayanan Medik, Departemen Kesehatan RI; 2007. 
[2] Poluan HHR, Kristatnto E, Wowor VNS. Gambaran Data Odontogram Rekam Medik Gigi di Balai Pengobatan Rumah Sakit Gigi dan Mulut Universitas Sam Ratulangi Manado. Manado: Universitas Sam Ratulangi.

[3] Murniwati. Peran Rekam Medik Gigi Sebagai Sarana Identifikasi. Majalah Kedokteran Andalas No. 2 2012; vol.36.

[4] Peraturan Menteri Kesehatan Republik Indonesia Nomor 269/Menkes/PER/III/2008 Tentang Rekam Medis. In: Indonesia KKR, ed. Jakarta: Kementerian Kesehatan Republik Indonesia; 2008.

[5] Panduan Rekam Medik Kedokteran Gigi. Jakarta: Sub-Direktorat Pelayanan Kesehatan Gigi dan Mulut, Direktorat Bina Upaya Kesehatan Dasar Kementerian Kesehatan RI; 2014.

[6] Peraturan Menteri Kesehatan Republik Indonesia Nomor 9 Tahun 2014 Tentang Klinik. In: Indonesia KKR, ed. Jakarta: Kementerian Hukum dan HAM Republik Indonesia; 2014.

[7] Morgan RG. Quality Evaluation of Clonical Records of a Group of General Dental Practitioners Entering a Quality Assurance Programe. British Dental Journal 191, Oktober 2012. p: 436-441

[8] Hatta G. Pedoman Manajemen Informasi Kesehatan di Sarana Pelayanan Kesehatan Jakarta: UI Press; 2012.

[9] Basuki S. Manajemen Arsip Dinamis. Jakarta: PT Gramedia Pustaka Utama; 2013.

[10] Huffman EK. 1999. Health Information Managemen Rev. Berwyn: Physicians Record Company.

[11] Yustiawan T. 2013. Manajemen Klinik Dalam Persiapan Kerjasama Dengan BPJS Kesehatan, Jurnal Administrasi Kesehatan Indonesia, Vol.1 No.3 p:208-216. 